\title{
NASATM-84306
}

NASA Technical Memorandum 84306

Airborne Astronomy Program

Medium Altitude Missions Branch

Preprint Series 001

组口.

NASA-TM-84306 19830005776

Submillimeter Extensions of the

Solar Limb Determined from

Observations of the Total

Eclipse of 1981 July 31

C. Lindsey, E. E. Becklin, J. T. Jefferies, F. Q. Orrall, M. W. Werner and I. Gatley

November 1982

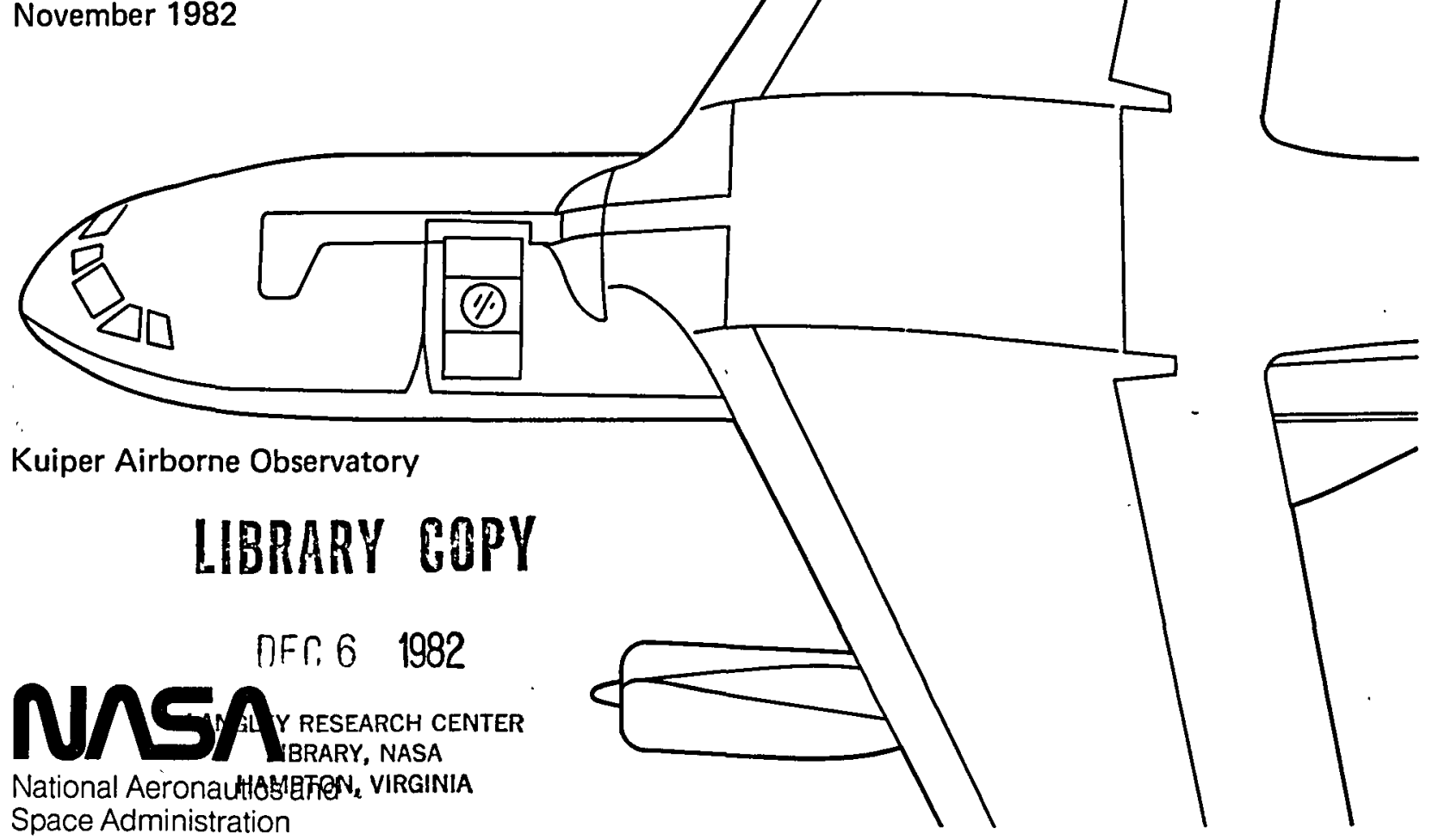




\section{Submillimeter Extensions of the Solar Limb Determined from Observations of the Total Eclipse of 1981 July 31}

C. Lindsey

E. E. Becklin

J. T. Jefferies

F. Q. Orrall, Institute for Astronomy, University of Hawaii

M. W. Werner, Ames Research Center, Moffett Field, California

I. Gatley, United Kingdom Infrared Telescope 


\section{SUBMILLIMETER EXTENSIONS OF THE SOLAR LIMB \\ DETERMINED FROM OBSERVATIONS OF THE \\ TOTAL ECLIPSE OF 1981 JULY 31}
C. LIndsey, E. E. Becklin, J. T. Jefferles, and F. Q. Orrall
Institute for Astronomy, University of Hawall
M. W. Werner
NASA-Ames Research Center
and
Ian Gatley
United Kingdom Infrared Telescope

Recelved September 1982

Accepted for publication in Astrophysical Journal Letters 


\section{ABSTRACT}

We present first results of observations of a lunar occultation of the solar limb made from the Kuiper Alrborne Observatory In the $30,50,100$, and $200 \mu \mathrm{m}$ continuum during the total solar eclipse of $1981 \mathrm{July} 31$. We find the solar limb to be extended at the longer wavelengths up to $1000 \mathrm{~km}$ higher than predicted from smooth plane-parallel chromospherlc models. Results at both second and third contact show the Infrared 1Imb extensions to be approximately $0^{n} .8,1^{*} .5,2^{*} .5$, and $3^{*} .0$ above the visible 1 imb in the $30,50,100$, and $200 \mu \mathrm{m}$ bands, respectively: A possible interpretation proposes chromospheric fine structure Inhomogenelties of greater density than presently incorporated In models of the middle chromosphere.

\section{DEDICATION}

We dedicate this work to David A. Barth, the chief pilot of the KAO during the eclipse observation, who traglcally lost his life while test-flying an alrcraft a few weeks after the successful completion of our program. Our observations required operation of the afrcraft at its performance 1imit, and we therefore depended very much on his skill. We were very fortunate not only In having the benefit of his outstanding ablitty, but also for the real pleasure of his personal acquaintance during his involvement with our program. 


\section{INTRODUCTION}

Observations in the infrared continuum provide a powerful LTE probe" of the teraperature and density structure of the solar atmosphere. The 30 to 200 $\mu$ m continuum 18 of particular importance, since it originates from the temperature minimum, where nonradiative heating becomes Important (cf., Thomas and Athay 1961).

The obstacles to making good solar observations at these wavelengths are that 1) the earth's atmosphere is opaque to most of the 30 to $300 \mu \mathrm{m}$ range, and 2) diffraction severely IImits angular resolution. Because of these difficulties, few solar observations exist in this entire spectral band.

The Kuiper Alrborne Observatory (RAO) is uniquely sulted to overcome both these problems, since it can fly a $0.9 \mathrm{~m}$ telescope to altitudes above $10 \mathrm{~km}$, where atmospheric extinction of infrared radiation is only a few percent (cf. Cameron et al. 1971) - Furthermore, the occultation of the solar Ifmb during an eclipse permits a determination of the solar limb intensity profile with high angular resolution. Smearing and displacement of the lunar shadow due to Fresnel diffraction are of the order

$$
\Delta \theta \lesssim\left(\frac{\lambda}{\text { Distance to Moon }}\right)^{1 / 2},
$$

which 1 s less than 0 ". 1 for wavelengths, $\lambda$, less than $200 \mu$. The practical 1imit to resolution is Imposed by the roughness of the lunar Iimb, whose helght distribution has a width of the order $l^{\text {" }}$. 
The overall eclipse experiment was designed to determine the Intensity profile of the quiet solar 11mb. In this first report we present a determination of the extensions of the Infrared IImbs above the visible limb. These results, obtained by timing the occultations at all wavelengths, show the $801 \mathrm{ar} 1 \mathrm{mmb}$ at $200 \mu \mathrm{m}$ to be extended up to three arc seconds beyond the visible limb. This extension is substantially greater than that computed for prevalling chromospherlc models in which the low chromospheric temperature miniwum region is homogeneous, smooth, and in approximate hydrostatic equilibrium.

The observations we describe were made from the KAO at an altitude of $13 \mathrm{~km}$ over the north Paclfic Ocean, close to the Kurlle Islands, north of Japan, during the total solar eclipse of 1981 July 31 . Both 2nd and 3rd contact occultations were observed in well-defined broad passbands centered near $30,50,100$, and $200 \mu \mathrm{m}$. All four passbands were monitored simultaneousiy at the same position on the limb.

A full analysis of the Infrared intensity profiles will be presented in subsequent papers.

\section{PROCEDURE}

The RAO telescope is a $0.9-\mathrm{m}$ Cassegrain with $\mathrm{f} / 17$ secondary optics. For solar observations, a filter of $6 \mathrm{~mm}$ thick high-density polyethylene was Installed over the primary mirror to reject visible light and prevent overheating of the telescope optics. This filter introduced optical aberrations that smeared the instrumental beam width to $\sim 100^{\circ}$ at $200 \mu$ m and to $\sim 130^{\circ}$ at $30 \mu \mathrm{m}$. 
The detector system was a dichroic cryogenic four-channel photometer (cf., Gatley et al. 1977). In this system Incoming radiation enters a 4 mm $\left(60^{\circ}\right)$ common focal-plane aperture, and is partitioned by dichrolc beamsplitters 1nto four well-defined passbands centered near $30,50,100$, and $200 \mu \mathrm{m}$, with fractional width $\Delta \lambda / \lambda \sim 0.3$. These bands are detected separately by four gallium-doped germanium bolometers. The infrared flux in the same region is thus monttored simultaneously in all four passbands.

Two-beam chopplng was used to compensate for varlable sky and telescope emissivity and to eliminate low-frequency electronic nolse in the detector system. In this technique the secondary mirror of the telescope is rocked at $30 \mathrm{~Hz}$ In a square-wave mode, so that the focal plane aperture alternately samples beams $2^{\prime}$ apart. The detector outputs are fed into phase-switched amplifiers, which extract the signal difference and thus continuousiy register the Infrared flux difference between the two beams. We define the "positive beam" and the "negative beam" according to the sign of the signal voltage produced by an infrared source in the respective beam.

In normal two-beam chopping the difference signal due to an unresolved source in one beam is sensitive to guiding errors. To solve this problem a $0.5 \mathrm{~Hz}$ triangular wave of $5^{\prime}$ amplitude was superimposed on the normal square-wave oscillation of the secondary mirror. This has the effect of sweepling both beams across the solar limb crescent, once each second.

This procedure is 11lustrated in Figure 1 for the occultation approaching second contact (a). As the negative beam sweeps across the limb crescent (cf. profile b), a negative signal (two-beam difference) results, closely followed 
by a positive deflection as the positive beam follows behind. The resulting profile is shown in (c). The ordinate range of this profile serves as a measure of the solar Intensity in the band swept by the beams.

The telescope was gyro-stabilized with a $1 \mathrm{~Hz}$ rms gulding jitter estimated at $2^{*}$ and a gulding drift of $2^{\mu / 8 e c . ~ A ~ v i s u a l ~ p o i n t i n g ~ r e f e r e n c e ~}$ was provided by a bore sighted gulde telescope. The trlangular-wave scan was centered onto the projected point of second contact on the solar $11 \mathrm{mb}$, where 1t was malntained for a full 20 seconds after visual second contact. The telescope was then moved across the moon to the projected point of third contact, where the foregoing sequence (In reverse) was repeated. The occultation rate, as vlewed from the moving alrcraft, was calculated 0 0 .46/sec. The total duration of visual totality was 888 .

\section{RESULTS}

Figure 2 shows the 30 and $200 \mu \mathrm{m}$ two-beam scan profiles across the solar IImb crescent from about 15 seconds preceding to 10 seconds following visual second contact. Profile 2(a) provides the positions of the center-point between the beams as they are scanned across the crescent. Profile 2(b) shows the resultant $200 \mu \mathrm{m}$ signal difference.

A $200 \mathrm{\mu m}$ signal difference for the lunar 11mb $1 \mathrm{~s}$ clearly present after the solar contribution has disappeared. This profile during totality was used to generate a representation of the lunar contribution throughout the occultation $2(c)$, which was subtracted from the $200 \mu \mathrm{m}$ profile (a) to represent the profile of the solar contribution alone (d). The $30 \mu \mathrm{m}$ occultation profile is shown in (e). 
The differences between the upper and lower envelopes of the two-beam difference plots define an occultation curve for the segment of the solar crescent scanned by the beams. These amplitudes are plotted in Figure 3 for 30 and $200 \mu \mathrm{m}$, at both second and third contact. The 50 and $100 \mu \mathrm{m}$ occultation curves fall between the 30 and $200 \mu \mathrm{m}$ prof1les. The lower, abscissa zeros are the points of visual second and third contact as determined by a video tape record of the gulde telescope Image.

Note that the $200 \mu \mathrm{m}$ occultation curve at second contact extrapolates to zero $2^{\circ}$ above the $30 \mu \mathrm{m}$ curve. The $30 \mu \mathrm{m}$ curve in turn extrapolates to zero $\sim 1^{\text {" }}$ above the v1sible 11mb. The $200 \mu \mathrm{m}$ 11mb 1s therefore a full $3^{\circ}$ above the visible limb. This result is confirmed at third contact. We contend that such large limb-extensions cannot be produced artificlally. Nelther Fresnel diffraction nor sudden 1Imb-brightening can conspire to extend the moment of occultation significantly.

Note that the occulation curves are approximately linear approaching contact. This indicates a relatively flat intensity profile approaching the extreme 11mb. The slope of the $200 \mu \mathrm{m}$ profile at third contact is $\sim 15 \%$ greater than at second contact. This Indicates a locally brighter limb, possibly assoclated with weak calclum plage near the point of third contact (cf. Hale regions 17754 and 17761).

The times of visible second and third contact were determined from a video tape record of the visual reference monttor used for gulding. Because of the increased vidicon gain during totality, our determination of the time of visible third contact was made with three times better precision than the time of second contact. The separation of the $30 \mu \mathrm{m}$ 11mb above the visible IImb at third contact was measured at $0^{\infty} .8 \pm 0^{\infty} \cdot 2$. This value 1 s also adopted 
for second contact, because of better timing of visual third contact. The IImb extensions for all wavelengths for both second and third contacts are 11sted in Table 1.

\section{DISCUSSION AND CONCLUSIONS}

The submilifmeter limb extensions determined by our occultation observations Increase progressively with wavelength from 0 ". $8(580 \mathrm{~km})$ above the visible 1 imb at $30 \mu \mathrm{m}$ to $3^{\mu}(2200 \mathrm{~km})$ at $200 \mu \mathrm{m}$. These heights are respectively $900 \mathrm{~km}$ and $2500 \mathrm{~km}$ above the base of the photosphere (defined by $\tau[5000 \mathrm{~A}]=1$ vlewed at disk center), which 11 es $340 \mathrm{~km}$ below the visible 11mb. These results are not easily understood in terms of smooth hydrostatic-equ1librlum model chromospheres made to flt radiometric measures of the solar continuum, Including all of the models of Vernazza, Avrett and Loeser (VAL 1981). The only known important submillimeter continuum opacity sources In the solar chromosphere are free-free absorption in $(e, p)$ and (e, H) collisions. These increase approximately as $\lambda^{2}$, and 80 are much greater for the longer wavelengths. At low chromospheric helghts in the VAL models, temperatures are much 1 ess than $6000 \mathrm{~K}$ and hydrogen is almost entirely neutral, so that (e, H) absorption dominates. Above $1200 \mathrm{~km}$, hydrogen lonlzation exceeds 1\%, generating strong (e, p) absorption, wh1ch dominates from thence upward. We calculate the $200 \mu \mathrm{m}$ limb helghts due to free-freeopacity to be less than $1500 \mathrm{~km}$ for all of the VAL models, approximately 1000 $\mathrm{km}$ below the observed helght.

It is hard to see how a simple modification of the smooth models can provide the extra chromospherlc opacity needed to ralse the $200 \mu \mathrm{m} 11 \mathrm{mb}$ the additional $1000 \mathrm{~km}$ required by the observations. Such a discrepancy strongly 
Indicates the existence of dense fine-structure Inhomogeneities in the middle chromosphere that depart from gravitational-hydrostatic equilibrium.

The sense of our results was somewhat to be anticipated from earlier results at longer wavelenghts. Beckman, Lesurf, and Ross (1975) claim a IImb extension of $4^{\circ}$ at In 400,800 , and $1200 \mu \mathrm{m}$ Horne et al. (1980) observed a IImb extension of the order of $8^{\prime \prime}$ at $1300 \mu \mathrm{m}$. These extensions have been attributed to chromospheric spicules (Beckman and Clark 1978), seen In Ha Images of the solar limb. Our observations must relate to simflar but denser lower-1ying fine structure.

Our results establish the existence of material of significant submillimeter opacity at helghts exceeding $2500 \mathrm{~km}$ above the base of the photosphere. An Important hypothesis is that the fine-structure materlal responsible for the extended limbs corresponds to the $6000 \mathrm{~K}$ hydrogen Ionlzation plateau, so prominent in all of the VAl models. The onset of hydrogen Ionization in this temperature region could provide strong (e, p) absorption to make the fine structure opaque to submillimeter radiation.

The $200 \mu \mathrm{m}$ disk-center brightness temperature 1s only $4500 \mathrm{~K}$ (Rast et al. 1978). Consequently, opaque $6000 \mathrm{~K}$ fine structure should brighten the limb considerably. A colder limb would require cooler and much denser fine. structure to generate the observed submillimeter IImb extensions. A resolution of this matter will depend on careful analysis of our data to determine the absolute 11mb brightness temperatures at the longer wavelengths.

We applaud the entire KAO staff for thelr extreme hard work, competence and enthuslasm, which made this spectal and difficult program a success. The Astrophysical Experiments Branch at NASA-Ames gave exemplary technical support. The staff and personnel of Yakota Alr Force Base In Japan gave us 
special hospltality and a comfortable and convenlent working situation. Marle R. McCabe provided us with valuable support from the Mees Solar Observatory. Our Japanese colleagues at Kyoto UnIversity and the University of Tokyo provided us with important updates on solar activity and strong support in making our operation in Japan possible. We regret. that space does not allow us to thank all those who worked so hard on this extremely difficult profect. Th18 work was supported in part by NASA grants NAG 2-59, NGL 12-001-011, and NASW-3159, the Royal Observatory of Edinburgh and by the NASA-Ames Research Center. 
TABLE 1

Submilifmeter Limb Extensions

\begin{tabular}{lll}
\hline$\lambda$ & Second contact & Third contact \\
\hline $0.5 \mu \mathrm{m}$ & $0^{\infty} .0 \pm 0^{\infty} .5$ & $0^{\infty} .0 \pm 0^{\infty} .2$ \\
$30 \mu \mathrm{m}(\mathrm{ref})$ & $0^{\infty} .8 \pm 0^{\infty} .0$ & $0^{\infty} .8 \pm 0^{\infty} .0$ \\
$50 \mu \mathrm{m}$ & $1^{\infty} .4 \pm 0^{\infty} .2$ & $1^{\infty} .7 \pm 0^{\infty} .2$ \\
$100 \mu \mathrm{m}$ & $2^{\infty} .2 \pm 0^{\infty} .2$ & $2^{\infty} .7 \pm 0^{\infty} .2$ \\
$200 \mu \mathrm{m}$ & $2^{\infty} .9 \pm 0^{\infty} .2$ & $3^{\infty} .2 \pm 0^{\infty} .2$ \\
\hline
\end{tabular}




\section{REFERENCES}

Beckman, J. E., Lesurf, J. C.. G., and Ros8, J. 1975, Nature, 254,38 ,...

Beckman, J. E., and Ros8, J. 1978, In Far Infrared Astronomy, ed. M. Rowan-Roblnson (Oxford: Pergamon Pres8), p. 79.

Cameron, R. M., Bader, M., and Mobley, R. E. 1971, Appl- Opt1c8 10, 211.

Gatley, I. I., Becklin, E. E., Werner, M. W., and Wynn-W1ll1ams, C. G. 1977, Ap. J., 216, 277.

Horne, R., Hurford, G. J., Z1rin, H., and de Graauw, T. 1980, Ap. J., 244, 340.

Orrall, F. Q•, Becklin, E. E•, Jefferles, J. T•, Lindsey, C., Werner, M. W., and Gatley, I. I. 1982, BAAS, 13, 880 .

Rast, J., Kneubuehl, F. R., and Mueller, E. A. 1978, Astr. Ap., 68, 229.

Thomas, R.' N., and Athay, R. G. 1961, Phys1cs of the Solar Chromosphere (New York: Interscience), p. 17.

Vernazza, J. E., Avrett, E. H., and Loeser, R. 1981, Ap. J. Suppl., 45, 635. 


\section{FIGURE CAPTIONS}

FIG. 1.-Schematic dlagram of two-beam chopping-8canning mode used for observing the solar limb crescent (a) - see text for details.

FIG. 2.-Two-beam difference profiles across the solar 11mb crescent at 30 and $200 \mu \mathrm{m}$ during the 2 nd contact $11 \mathrm{mb}$ occultation - see text for deta11s.

FIG. 3 -Occultation curves at 30 and $200 \mu \mathrm{m}$ at second and third contact. The bottom abscissa zeros represent the points of visual contact. The upper abscissa zeros reference the base of the solar photosphere $(340 \mathrm{~km}$ below the visible limb. 


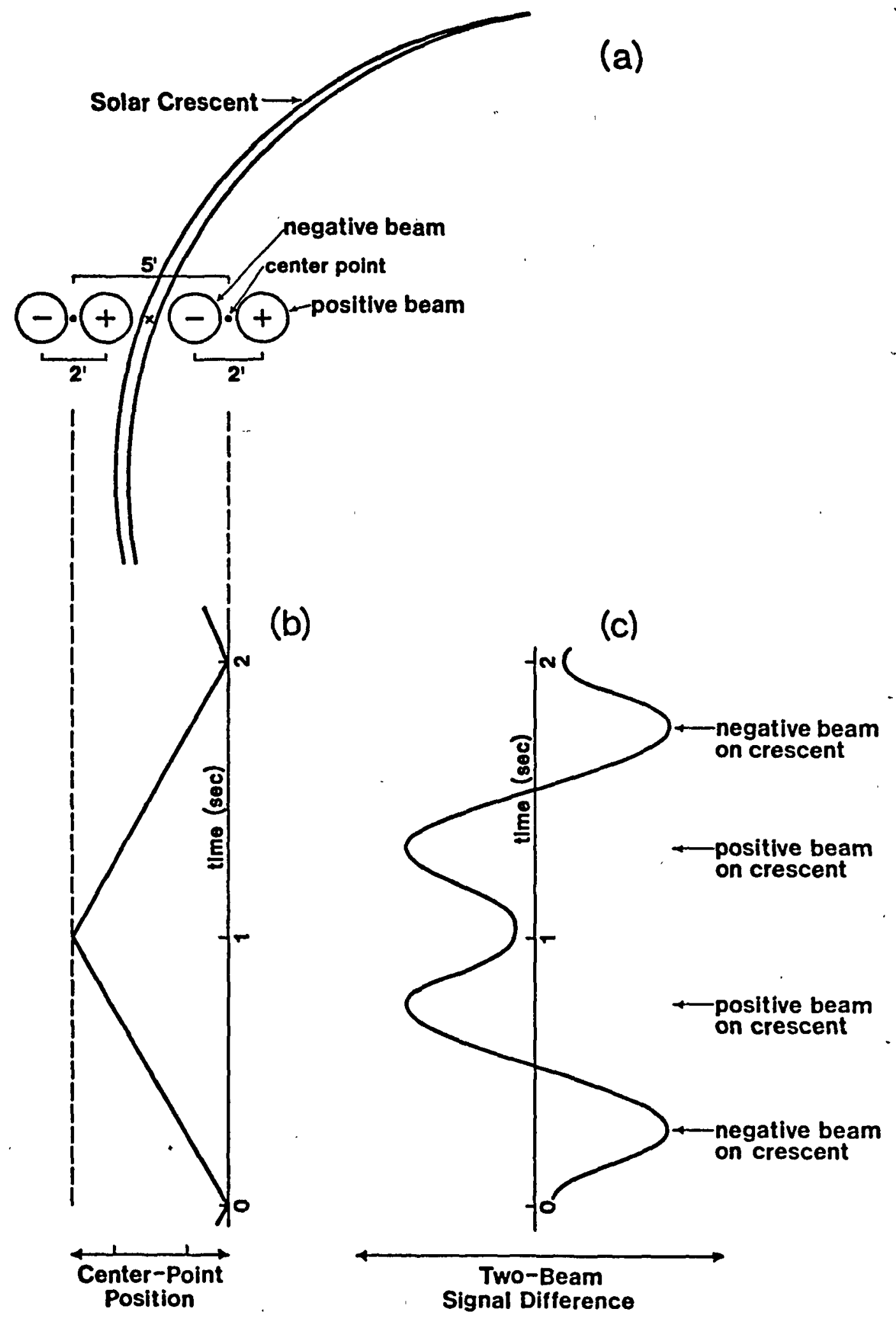




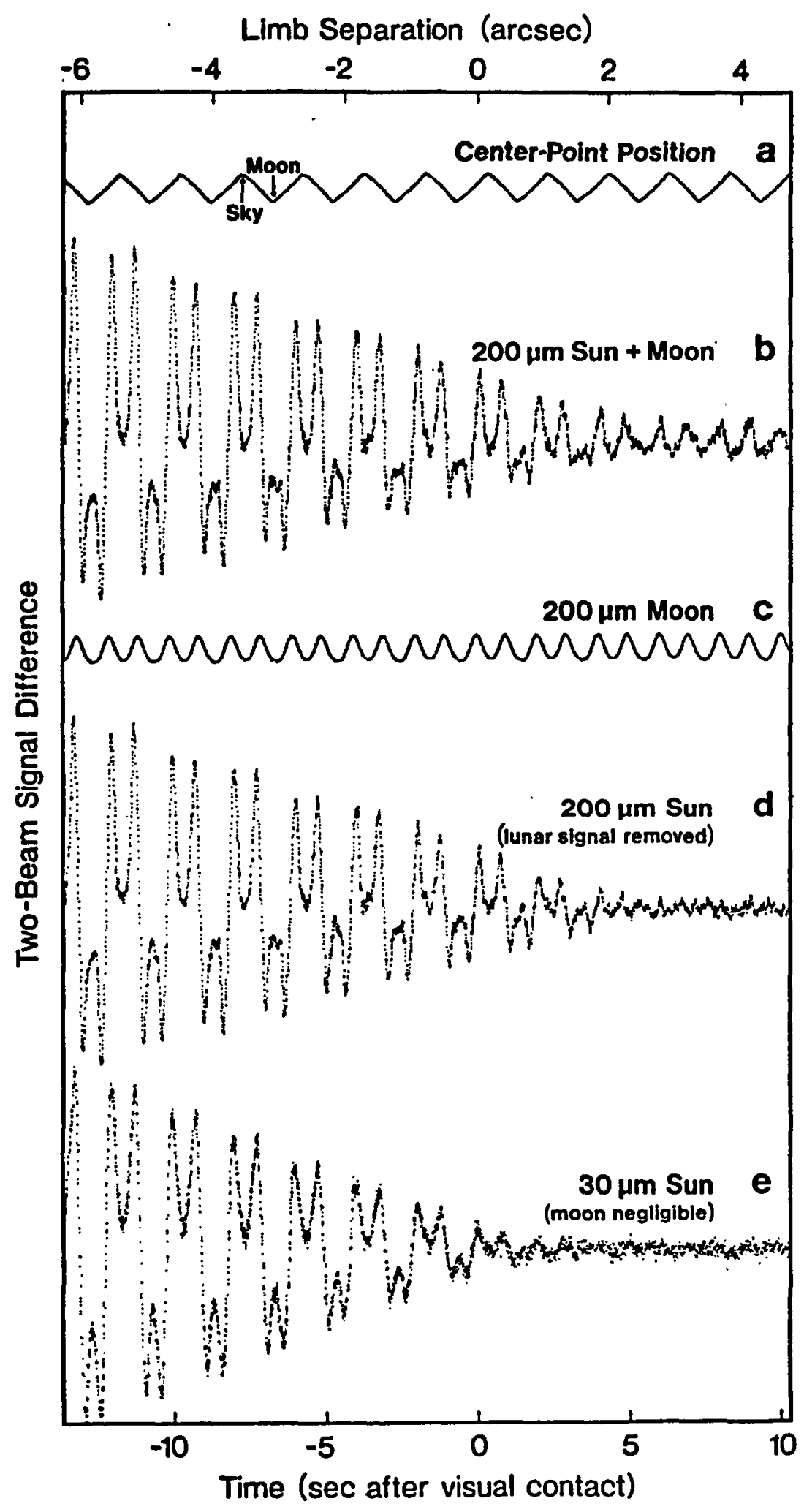




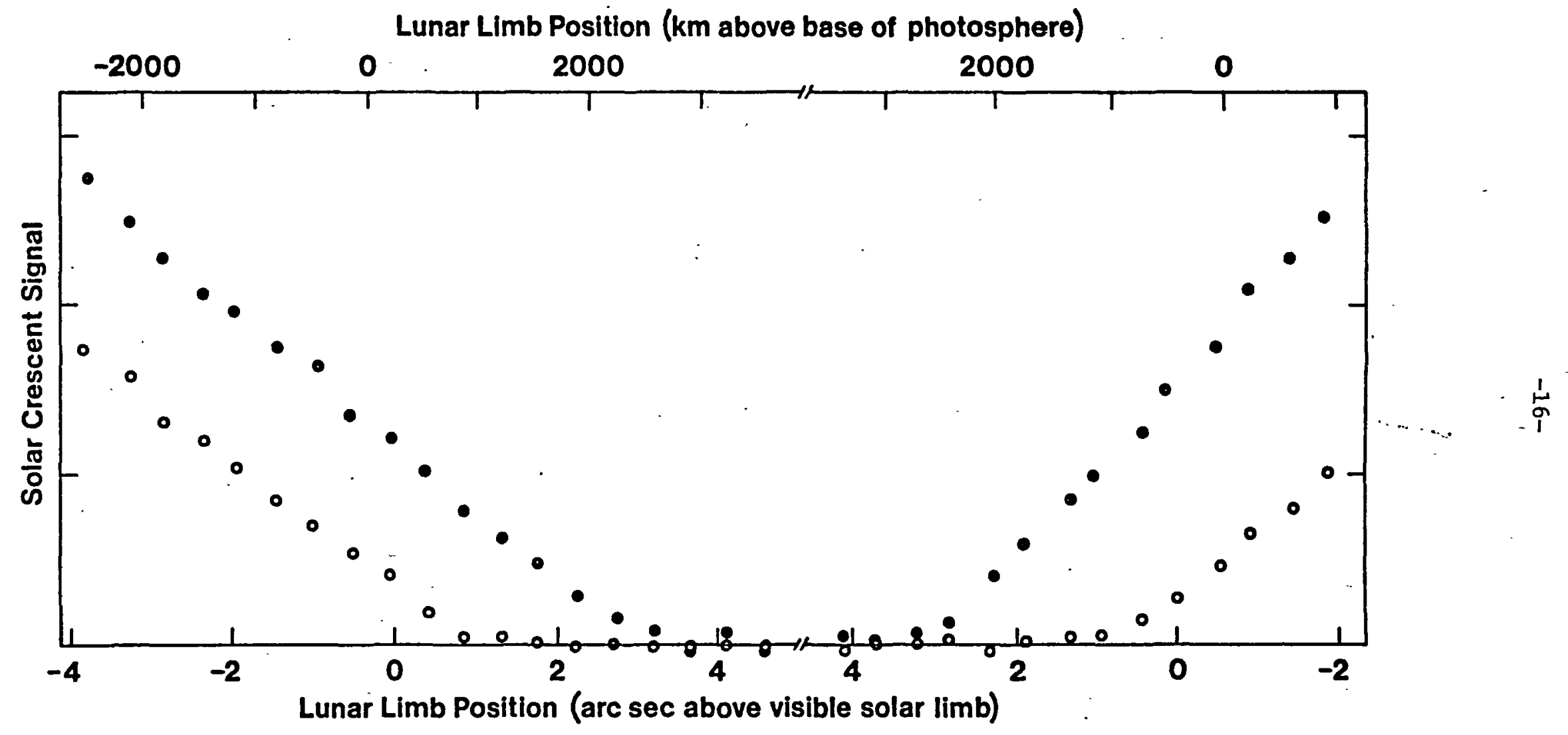




\begin{tabular}{|c|c|}
\hline $\begin{array}{l}\text { 1. Report No. } \\
\text { NASA TM-84306 }\end{array}$ & 2. Government Accession No. \\
\hline $\begin{array}{l}\text { 4. Title and Subtitle } \\
\text { SUBMILLIMETER EXTENSIONS OF THE } \\
\text { OBSERVATIONS OF THE TOTAL ECLIPS }\end{array}$ & $\begin{array}{l}\text { SOLAR IIMB DETERMINED FROM } \\
\text { SE OF } 1981 \text { JULY } 31\end{array}$ \\
\hline $\begin{array}{l}\text { 7. Author(s) } \\
\text { C. IIndsey,* E. E. Beckl1n,* J, } \\
\text { M. W. Werner, } * * \text { and Ian Gatley }\end{array}$ & T. Jefferies, F. Q. Orrall,* \\
\hline
\end{tabular}

9. Performing Organization Name and Address

*Institude for Astronomy, University of Hawail, Honolulu, Hawaif

**Ames Research Center, Moffett Field, Calif. and

tUnited. Kingdom Infrared Telescope, H110, Hawal1

12. Sponsoring Agency Name and Address

Nationa1 Aeronautics and Space Administration

Washington, D.C. 20546

3. Recipient's Catalog No.

5. Report Date November 1982

6. Performing Organization Code

8. Performing Organization Report No. A-9154

10. Work Unit No. 352-02-03

11. Contract or Grant No. NAG-259, NGL 12-001-011, and NASW-3159

13. Type of Report and Period Covered Technical Memorandum

15. Supplementary Notes

Preprint Series \#1. Supported by NASA grants. Point of Contact: L. C. Haughney, Ames Research Center, Moffett Field, Calif. 94035, M/S 211-12, (415) 965-5339, FTS 448-5339

16. Abstract

We present first results of observations of a lunar occultation of the solar limb made from the Kuiper Airborne Observatory in the $30,50,100$, and $200 \mu \mathrm{m}$ continuum during the total solar eclipse of 1981 July 31 . We find the solar limb to be extended at the longer wavelengths up to $1000 \mathrm{~km}$ higher than predicted from smooth plane-parallel chromospheric models. Results at both second and third contact show the infrared limb extensions to be approximately $0 " .8,1^{\prime \prime} .5,2^{\prime \prime} .5$, and $3^{\prime \prime} .0$ above the visible 1 imb in the $30,50,100$, and $200 \mu \mathrm{m}$ bands, respectively. A possible interpretation proposes chromospheric fine structure inhomogeneities of greater density than presently incorporated in models of the middle chromosphere.

17. Key Words (Suggested by Author(s)) 18. Distribution Statement Unlimited

Submillimeter observations Solar $11 \mathrm{mb}$

Solar eclipse

STAR Category - 92

19. Security Classif. (of this report)

20. Security Classif. (of this pagel

21. No. of Pages Unclassified Unclassifled 